3. Aufgerichtliche Chemie bezügliche Methoden.

\title{
H. Fresenius.
}

Ueber den Nachweis des Strychnins im Gehirn. D ragend orff ist es nie gelungen, Strychnin nach Vergiftungen im Gehirn aufzufinden. H. Lajoux und Grandval*) hatten den Leichnam eines Kranken zu untersuchen, der tinct. nuc. vom. als Einspritzung und per os erhalten hatte, im Ganzen nach der Verfasser Berechnung 2,353 $\mathrm{g}$, worin höchstens $0,0035 \mathrm{~g}$ Strychnin enthalten sein konnten. Bei dieser Leiche gelang es den Verfassern das Alkaloid im Gehirne unzweifelhaft nachzuweisen. $410 \mathrm{~g}$ Gehirn wurden mit Alkohol verrieben, das Gemenge unter Zusatz von Weinsäure 3 Stunden lang im Wasserbade bei $80^{\circ}$ digerirt, durch Leinen gepresst, der Rückstand von neuem in Alkohol zertheilt, zwei Stunden digerirt, desgleichen noch ein drittes Mal. Die Filtrate wurden eingedampft, der wässerige Rückstand durch fenchtes Papier filtrirt und das Filtrat mit Aether ausgeschüttelt. Hierauf setzte man zur wässrigen Lösung Ammoniak und schüttelte mit Chloroform aus. Der Abdampfungsrückstand des Chloroformextractes wurde mit concentrirter Schwefelsäure behandelt um noch vorhandene fremde organische Substanzen zu verkohlen.

Nach dreimaliger Behandlung mit Chloroform und concentrirter Schwefelsäure erhielten die Verfasser einen sehr geringen, farblosen Rückstand, der die Reactionen des Strychnins in unzweifelhafter Weise lieferte.

Zur Nachweisung des Blutes. Um bei Untersuchung von Blutflecken die Häminkrystalle stets sicher zu bekommen empfiehlt F. Selmi**) das betreffende Object einige Zeit mit Ammoniakflüssigkeit zu maceriren, die abgegossene oder abfiltrirte Flüssigkeit mit wolframsaurem Natron and Essigsäure zu fällen, den Niederschlag zu waschen und dann eine Mischung von 1 Vol. Ammoniakflüssigkeit und 8 Vol. absolutem Alkohol auf denselben einwirken zu lassen. Die weingeistige Flüssigkeit wird verdunstet und der dabei hinterbleibende Rückstand unter dem Mikroskope mit Eśsigsäure und Kochsalz behandelt, wodurch, wenn Blut vorhanden war, die Häminkrystalle sehr deutlich zum Vorschein kommen.

*, Journ. de pharm. et de chim. 30 u. Pharm. Centralhalle 20, 374.

**) Journ. de pharm. et de chim. Febr. 1879 u. Zeitschr. d. österr. Apothekervereins $\mathbf{1 7}$, 214.

Fresenins, Zeitschrift. XIX. Jahrgang. 